\title{
The effect of gravity drainage mechanism on oil recovery by reservoir simulation; a case study in an Iranian highly fractured reservoir
}

\author{
K. Zobeidi ${ }^{1} \cdot$ M. Mohammad-Shafie ${ }^{1} \cdot$ M. Ganjeh-Ghazvini ${ }^{1}$
}

Received: 14 September 2021 / Accepted: 14 December 2021 / Published online: 29 December 2021

(c) The Author(s) 2021

\begin{abstract}
A comprehensive reservoir simulation study was performed on an oil field that had a wide fracture network and could be considered a typical example of highly fractured reservoirs in Iran. This field is located in southwest of Iran in Zagros sedimentary basin among several neighborhood fields with relatively considerable fractured networks. In this reservoir, the pressure drops below the saturation pressure and causes the formation of a secondary gas cap. This can help to better assess the gravity drainage phenomenon. We decided to investigate and track the effect of gravity drainage mechanism on the recovery factor of oil production in this field. In this study, after/before the implementation of gas injection scenarios with different discharges, the contribution of gravity drainage mechanism to the recovery factor was found more than $50 \%$. Considering that a relatively large number of studies have been conducted on this field simultaneously with the growth of information from different aspects and this study is the last and most comprehensive study and also the results are extracted from real field data using existing reservoir simulators, it is of special importance and can be used by researchers.
\end{abstract}

Keywords Naturally fractured reservoir · Gravity drainage $\cdot$ Oil production mechanisms · Flow simulation · Matrix block height $\cdot$ Gas injection

\section{Introduction}

Gravity drainage as one of the mechanisms of natural fractured reservoirs is a process in which the gravity acts as the main driving mechanism in which the non-wetting phase (i.e., gas phase) pushes the oil out of the rock. It is an effective production mechanism in the gas-invaded zone due to a larger density difference. Dumore and Schols (1974) reported that due to gravity drainage in high permeability sandstone core, the oil residual saturation could be as low as $5 \%$. Clemens and Wit (2001) showed that the drainage rate is further reduced if there are no fractures in the horizontal plane, and the oil has to flow sideways toward the fracture system resulting in lower drainage rates. Verlaan and Boerrigter (2006) discussed the behavior of immiscible GOGD (gas/oil gravity drainage) as compared to fully miscible gas through modeling the behavior of a matrix block. Tan and Firoozabadi (1995) discussed that the absence of

K. Zobeidi

kzobeidi@ut.ac.ir; kzobeidi231@gmail.com

1 National Iranian Oil Company (NIOC), Tehran, Iran re-imbibition in miscible GOGD had a major impact on the oil production from heterogeneous stacks.

Bahari Moghaddam and Rasaei (2015) described that gravity drainage phenomenon can be classified into two main types: free-fall and forced gravity drainage. Free-fall gravity drainage is usually the major oil production mechanism in high permeability and thick reservoirs with a great drawdown pressure, while forced gravity drainage is a result of gas injection. The discussion of gravity drainage can be regarded as analytically, numerically and experimentally. Hagoort (1980) presented analytical solutions for an immiscible gas/oil drainage flow in a homogeneous stack in the absence of capillary pressure. Also Abbasi et al. (2018) modeled the gravity drainage process analytically for a 1-D single matrix block by considering gravity and capillary forces. In that work, after extending the obtained equations to a stack of matrix blocks, the effect of the re-infiltration process was investigated. Boerrigter et al. (2007) presented a dual permeability simulation formulation capable of handling GOGD and expansion imbibition processes, impact of fracture spacing, block height, GOGD of sub grid-block effects, re-imbibition effects and interaction of GOGD with EOR processes. Zobeidi et al. (2015a, b) described the 
simulation of one-phase miscible gravity drainage performance of a stack of matrix blocks. Also Rahmati and Rasaei (2019) discussed gravity drainage numerically. In this work, a mathematical computer program is developed to numerical simulation. Finally, this work shows $40 \%$ effect for gravity drainage in recovery factor. Sajjadian et al. (1999) performed laboratory studies of gravity drainage in fractured rock investigating the effect of capillary continuity and reinfiltration. The results of their experimental work discussed the effective parameters on re-infiltration process. Zobeidi et al. $(2015 \mathrm{a}, \mathrm{b})$ described the results of several experiments that were carried out to investigate the block-to-block interaction in fractured limestone reservoirs for both gas/oil and solvent oil systems by use of carbonate cores. The focus of this research was to understand gravity drainage, re-infiltration and mixing in fractured systems with a set of laboratory experiments. Also Zendehboudi et al. (2011) discussed the gravity drainage experimentally.

Zobeidi and Fassihi (2018) showed the importance of block-to-block interactions in miscible/immiscible gas/oil gravity drainage as well as solvent injection process. Ahmed (2018) has reported cases where the oil recovery of gravity drainage has exceeded $80 \%$ of the initial oil in place.

In addition to gravity drainage, other production mechanisms such as gas cap expansion (gas influx), fluid expansion, rock compaction and water influx are usually involved in oil production of a naturally fractured reservoir. These mechanisms rarely have equal share in oil recovery because each of them depends on a particular set of factors. The knowledge about the relative magnitude of their contributions has some practical advantages. It can help someone better understand the reservoir behavior or plan more effective IOR/EOR methods. For example, if water influx was recognized as the dominant mechanism, one would expect the problem of high water-cut production and might search for a promising water shut-off treatment. A well-known conventional method to quantify mechanisms' contribution is the rearranged form of the material balance equation (Pirson 1958). In the method, three fractions called DDI, SDI and WDI with sum unity describe depletion drive index, segregation (gas cap) drive index and water drive index, respectively. However, no specific distinct term represents gravity drainage.

To the best of our knowledge, few documents may be found in the literature to explicitly quantify the share of oil production due to gravity drainage in a real case. A technical difficulty is how to separate the contribution of gravity drainage from that of the gas influx. This study shows how the result of a commercial simulator can be analyzed to identify the contribution of gravity drainage. For an Iranian highly fractured reservoir, a representative model is created and then undergoes the history matching process. Oil production is predicted under two different conditions where the gravity drainage is active or inactive. The recovery factors and cumulative oil productions of these two cases are then discussed at natural depletion and gas injection scenarios. A sensitivity analysis on matrix block height is also conducted to explore its effect on recovery factor and pressure of the reservoir. Moreover, a graphical method applied on the capillary pressure curve is devised to determine the ultimate recovery factor. Finally, the results of this simple method are compared with those of the numerical simulation for evaluation purposes.

\section{A brief summary of reservoir data}

The studied field consists of an onshore anticline located in Zagros sedimentary basin in southwest of Iran. Its dimensions are $35^{*} 6 \mathrm{~km}^{2}$ along the NW-SE and NE-SW directions. The north and south flanks of the field have the maximum dip of $40^{\circ}$ and $54^{\circ}$, respectively. Geochemistry analysis showed that hydrocarbon of the reservoir has come from kerogen type II implying a marine depositional environment. Two formations called Asmari (the upper one) and Pabdeh (the lower one) make up the reservoir layer. Asmari formation has the thickness of about $410 \mathrm{~m}$ and consists mainly of limestone and dolomite. In this formation, whereas small amounts of anhydrite and sandstone may be found, the amount of shale can reach about $20 \%$ in rock volume especially at deeper sub-zones. Pabdeh is more than $380 \mathrm{~m}$ in thickness and generally consists of argillaceous limestone and shale. The limestone of the reservoir belongs to the classes of mudstone to wackestone primarily and wackestone to packstone secondarily. In this field, the quality of reservoir rock broadly decreases from the top to the bottom and from the central part of the field in the crest area toward the sides. The original oil in place (OOIP) of this reservoir is estimated to be 11 MMMSTB and about $9 \%$ of the total oil is in the fracture network. The initial hydrocarbon column was $1700 \mathrm{~m}$ approximately.

\section{Performance production analysis}

The production history of the field can be divided into 5 periods on the basis of production rates, oil and gas pressures as well as fluid contacts that are shown in Figs. 1,2 and 3.

- First period (1964-1970):

This period is the beginning of production from this field. Production during this period was mainly due to rock and fluid expansion and solution gas drive mechanisms and the average pressure has changed from 4640 to 4078 psi. Also, the cumulative production during this period was 193 million barrels. 


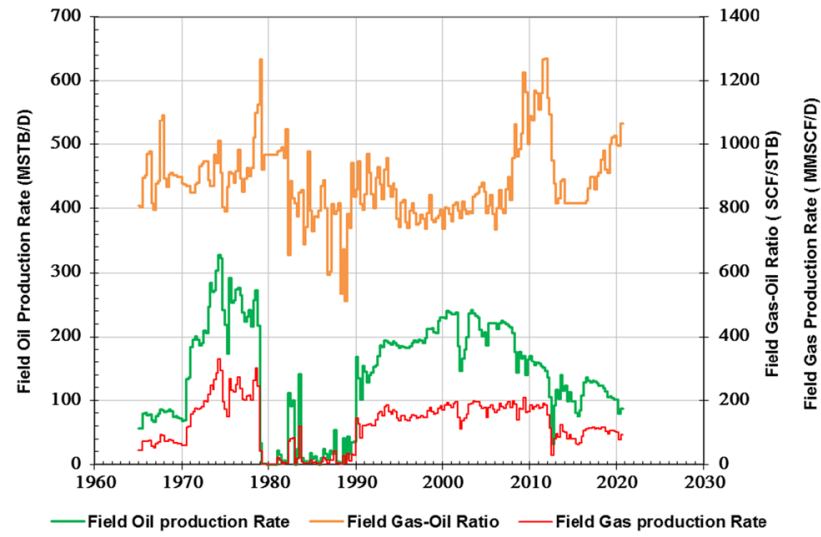

Fig. 1 Production history of the field

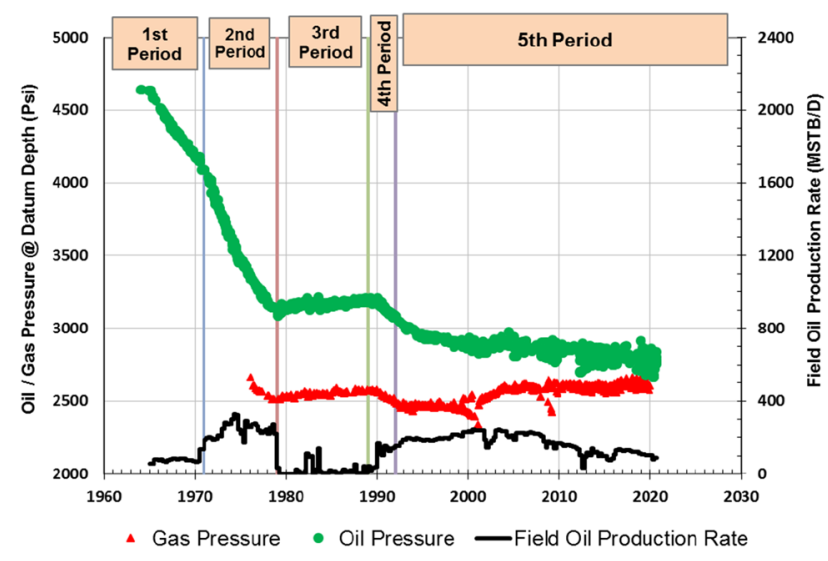

Fig. 2 The history of gas and oil pressure in the field

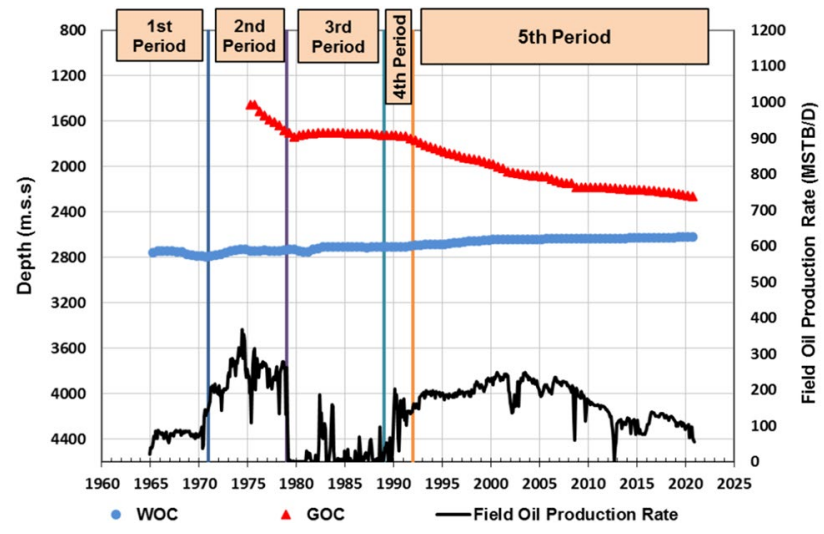

Fig. 3 The history of contact depths in the field

- Second period (1971-1978)

During this period, the gas cap was created and activated. Despite the expansion of the gas cap due to increase in the number of wells and oil production, the pressure of the reservoir dropped from 4078 to 3098 psi (Fig. 2). Due to the lack of a gas observation well in the gas cap during the first 5 years of the period, no real data on gas pressure were available that made the estimate of gas/oil contact unreliable. For the rest of the period, Fig. 3 shows the gas/oil contact has been coming down implying expansion of the gas cap. The cumulative production by the end of this period was 886 and the net production 693 million barrels. The gravity drainage mechanism was expected to start in the matrix blocks surrounded by the gas in the gasinvaded zone.

- Third period (1979-1988)

During this period, due to Islamic Revolution of Iran and Iran-Iraq war, production from the reservoir was reduced to a minimum of about 21 MSTBD and the cumulative production reached 963 million barrels. The low production rate and the partial support of the aquifer could reverse the downward trend of the pressure so that it increased by 100 psi in 8 years (Fig. 2). The water/oil contact slightly changed which indicated the aquifer of the reservoir was relatively weak (Fig. 3). In this period, the dominant mechanisms were the expansion of gas cap, the solution gas and water drives. For the matrix blocks in the finite volume of the gas cap, the gravity drainage also had an effect on oil production. Due to very little production, the reservoir pressure improved and rose to 3187 psi.

- Fourth period (1989-1991)

During this relatively short period, production has continued by the natural depletion and the dominant mechanism has been the gas cap expansion and the cumulative production and pressure of the reservoir also reached 1150 million barrels and 3099 psi, respectively.

- Fifth period (1992-until now)

Initial studies have shown that by injecting gas about 800 MMSCFD and after injecting 8474 MMSCF, the initial crest reservoir pressure could rise to 3600 psi. For this purpose, a gas injection project was commissioned. Unfortunately, the gas required for the injection was not sufficiently supplied, and so far the average daily rate, cumulative oil production and gas pressure at the crest have been 237.4 MMSCFD, 2.4 TCF and 2483, respectively. Figure 2 shows that the gas pressure was firstly stabilized and then has increased slowly after gas injection started. Moreover, the slope of oil pressure drop became smaller and finally stabilized due to the decrease in oil production rate and partial support from the aquifer.

At present, the daily oil rate, cumulative oil production and the reservoir pressure are 85 MSTBD, 2.83 MMMSTB and 2784 psi, respectively. During this period, the role of gravity drainage in oil production becomes increasingly prominent when a growing number of matrix blocks are

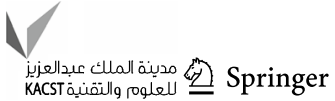


Table 1 Reservoir and fluid properties

\begin{tabular}{ll}
\hline Parameters & Values \\
\hline$P_{i}$ (Initial pressure) (psi) & 4640 \\
$T\left({ }^{\circ} \mathrm{F}\right)$ & 180 \\
Bubble point pressure (psi) & 3345 \\
${ }^{\circ}$ API & 34 \\
Solution gas/oil ratio (scf/stb) & 1069 \\
Oil formation volume factor & 1.55 \\
Oil formation volume factor @ $\mathrm{P}_{\mathrm{b}}$ & 1.58 \\
Oil density @ 3775 Psi (lb/ft $\left.{ }^{3}\right)$ & 40.9 \\
Gas density @ 3775 Psi (lb/ft $\left.{ }^{3}\right)$ & 13 \\
\hline
\end{tabular}

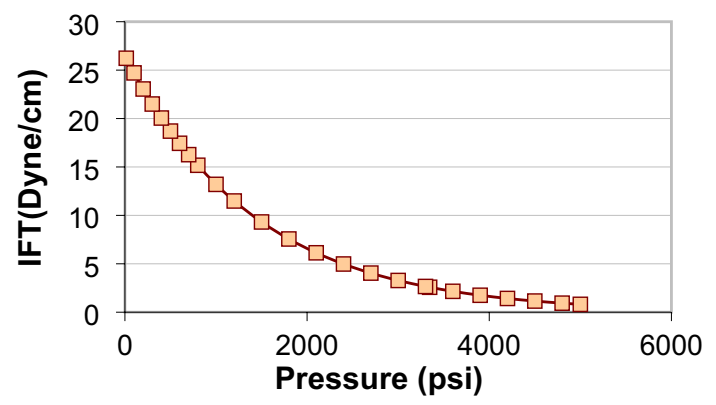

Fig. 4 Surface tension of representative sample versus pressure

located in the developing gas cap due to continuous gas injection and coming down the gas/oil contact by about $500 \mathrm{~m}$ as shown in Fig. 3.

\section{Fluid properties}

Some fluid properties are summarized in Table 1.

In this field, four bottom-hole fluid samples in wells 1, 3, 6 and 10 were taken, and complete $P, V$ and $T$ tests have been performed on them. According to the studies conducted in this section, due to proper lateral and vertical communication, there are no changes in the properties of the fluid in the region and depth, so one type of oil was considered throughout the reservoir at the initial conditions. This behavior is conceivable and expected due to the wide fracture network.

Convection and diffusion mechanisms in the fracture networks for many years have led to mixing of reservoir oil and providing homogeneous fluid properties. Since interfacial tension (IFT) versus pressure is required in reservoir simulation, it is shown in Fig. 4.

\section{Rock properties}

In this field, core operations have been performed on the samples taken from wells 1, 2, 4 and 7 (for routine tests) and the well 14 (for special tests). The average porosity and permeability of the reservoir is $6.38 \%$ and $2.85 \mathrm{md}$, respectively. The relationship between permeability and porosity is defined as follows.

$K=0.08698 \exp (0.16935 \varphi)$

Analysis of reservoir rock properties plays a very important role in the evaluation and management of oil reservoirs. The initial and final fluid saturation values as well as the shape of relative permeability diagrams and capillary pressures largely determine the hydrocarbon depletion processes. Thirty-four rock samples taken from the reservoir were used for special core analysis; 27 capillary pressure (drainage) tests, 6 gas/oil relative permeability tests and 3 water/oil relative permeability tests were conducted.
Fig. 5 Air-brine drainage capillary pressure of samples

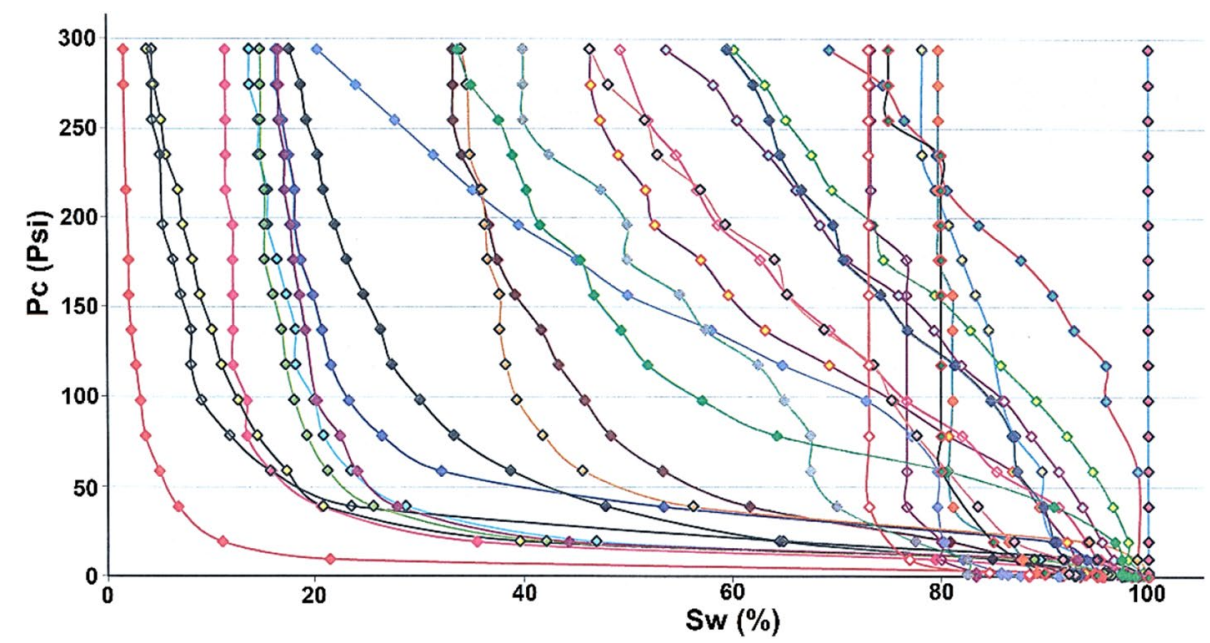


Table 2 Rock-type characteristics and corresponding end points

\begin{tabular}{llllll}
\hline RT & $<$ SW $<$ & $<$ PHI $<$ & Sorw & Sorg & Slc \\
\hline 1 & {$[0-20]$} & $\leq 14$ & 0.37 & 0.22 & 0.32 \\
1 & {$[0-10]$} & $>14$ & 0.37 & 0.22 & 0.32 \\
2 & $(10-20]$ & $>14$ & 0.30 & 0.17 & 0.32 \\
3 & $(20-40]$ & $\leq 9$ & 0.48 & 0.33 & 0.64 \\
4 & $(20-40]$ & $(9-12]$ & 0.40 & 0.26 & 0.56 \\
5 & $(20-40]$ & $>12$ & 0.33 & 0.20 & 0.47 \\
6 & $>40$ & $>4.77$ & 0.43 & 0.305 & 0.785 \\
\hline
\end{tabular}

Figure 5 illustrates the capillary pressure curves for different samples in the air-brine system.

After transforming raw Pc curves to Leverett J-function, 6 different rock types were recognized. These rock types could be successfully distinguished from each other by porosity and water saturation as the differential parameters. The characteristics and end points of each rock type are given in Table 2.

Figures 6 and 7 depict the capillary pressure and relative permeability curves of gas/oil system used in the simulation model.
Fig. 6 The gas/oil relative permeability curve of each rock type
Fig. 7 The gas/oil drainage capillary pressure curve of each rock type at $2600 \mathrm{psi}$
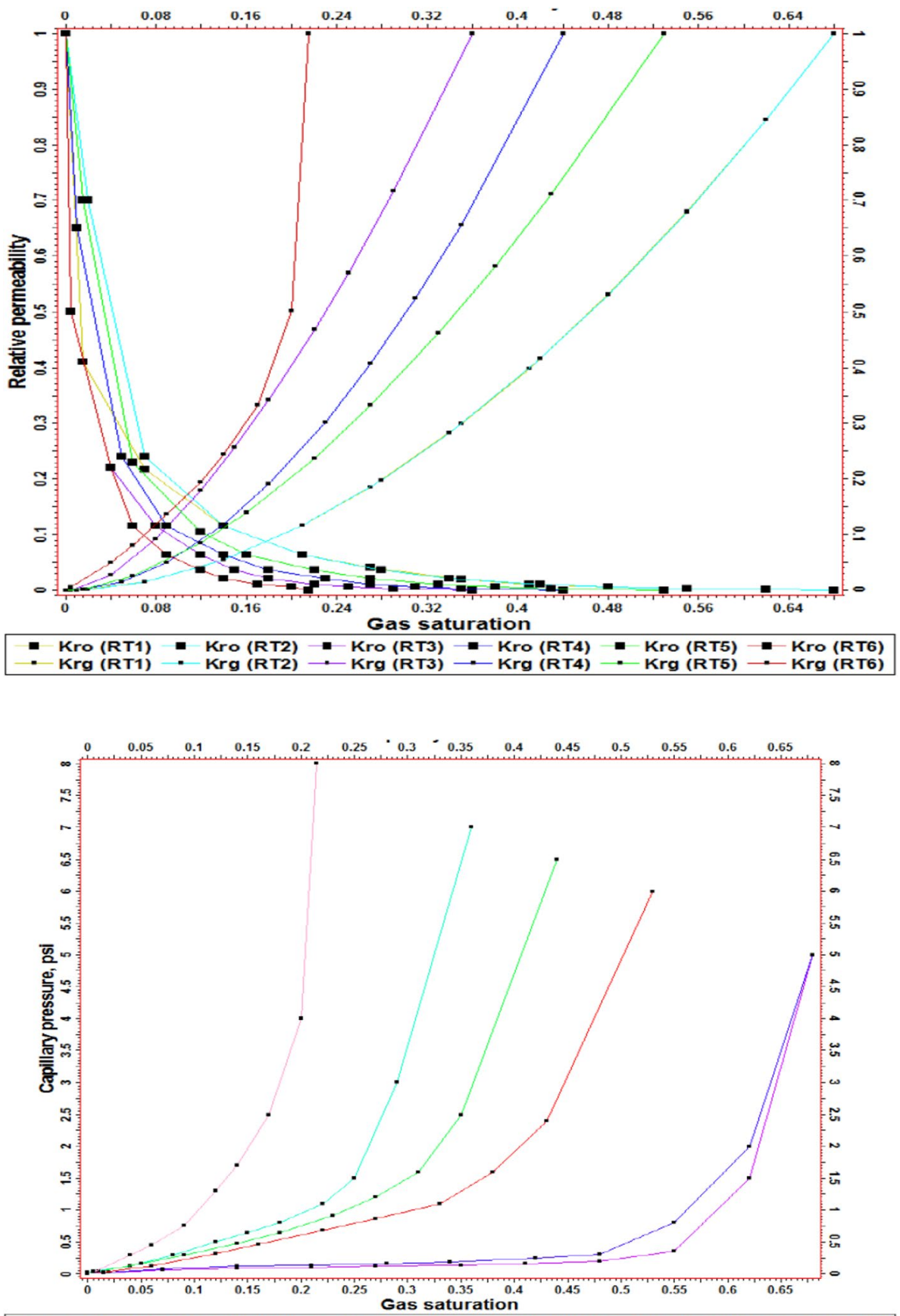

Gas-oil capillary pressure (RT1) : Gas-oil capillary pressure (RT3) - Gas-oil capillary pressure (RT5)
Gas-oil capillary pressure (RT2) : Gas-oil capillary pressure (RT4) : Gas-oil capillary pressure (RT6) 


\section{Simulation model}

Sixteen faults were detected throughout the reservoir based on seismic interpretations, geological, petrophysical and well test data obtained from 30 wells drilled into the field. These data were also used to build a high-resolution model that consisted of $50 \times 150 \times 259$ grids along the $x, y$ and $z$ axis, respectively. The fine grid model was then converted into a coarser one through an upscaling process. The coarse model having $48 \times 136 \times 30$ grids was made in dual porosity/single permeability form that doubles the total number cells; half of grid blocks point to the matrix medium, however, the other half present the fracture. A typical coarse grid was $510 \mathrm{ft}$ in length, $773 \mathrm{ft}$ in width and $79 \mathrm{ft}$ in thickness. This resolution was selected so that the main geological and petrophysical features of the reservoir (e.g., heterogeneity, faults, fluid contacts, etc.) were well preserved while simulation runs could be finished within a reasonable time.

A commercial simulator (Eclipse 2016) was employed to predict the flow behavior of the reservoir with a production history of more than 47 years. The aquifer was modeled by 2 weak Carter-Tracy analytical ones. Although the reservoir was initially under-saturated, the model showed that a secondary gas cap would form in the crest about 4 years after the start of production. After 28 years of oil production under natural depletion, a gas injection plan was approved to maintain the reservoir pressure and to continue the oil production. Dry gas with an average rate of 240 MMSCFD has been injected into the gas cap of the reservoir since that time. At present, 22 (16 production and 6 gas injection) wells are active in the field. Others are either observational or abandoned.

The reservoir model underwent a thorough history matching process to ensure that it could generate as accurate results as possible. The matching variables included the oil/gas production rates of wells and the reservoir in total, static and flowing bottom-hole pressures as well as the fluid contacts. These data were examined for validity before they were used in the history matching process. For example, the fluid contacts estimated by static pressures in observational and production wells were checked with the work-over job and performance of the wells. This approach helped to reduce uncertainty or possible errors. According to previous experiences in simulation of fractured reservoirs, those parameters with a considerable deal of uncertainty that could have a great effect on the reservoir behavior were designated as tuning parameters. Fracture properties such as porosity and permeability distribution, matrix block height, the shape factor in the transfer function and characteristics of the aquifers were among these parameters. Figure 8 illustrates a few examples implying that the tuned model has been able to adequately predict the actual behavior of the reservoir.

After successfully history matching, this model was used to investigate the effect of gravity drainage mechanism. In the forecast scenarios, 10 production wells and 1 new gas injection well were added to the existing ones. The simulator will open these wells in order, if necessary, to achieve the planned production rate.

Different scenarios with injection rates of 250,400 , 500, 600 and 800 MMSCFD were considered to find the optimal gas injection rate. A tight constraint was imposed on the reservoir pressure in all scenarios. The gas was being injected at the pre-specified rate, provided that the reservoir pressure did not exceed the minimum pressure at initial conditions (i.e., the pressure at the crest). Otherwise, the injection rate was adjusted to follow the restriction. This constraint would prevent a possible damage to the cap rock of the reservoir.

The reservoir pressure and the cumulative oil production volume for these scenarios are compared in Figs. 9 and 10, respectively. Figure 9 shows that the final reservoir pressure is the same for all scenarios due to the constraint discussed earlier. However, the reservoir pressure is elevated more slowly in scenarios with less injection rates. The behavior of cumulative oil production seems more complicated. Figure 10 indicates this variable (and hence the recovery factor) rises as the injection rate is increased up to 500 MMSCFD, whereas it little changes at the higher injection rates. Higher injection rate results in higher reservoir pressure which can smooth the way for oil flowing through the reservoir. At the injection rates greater than 500 MMSCFD, the positive effect of pressure is offset by the faster downward movement of the gas/oil contact (GOC). If the GOC comes down more rapidly, upper perforations of some wells are soon surrounded by the gas phase which leads to the higher produced gas/oil ratio (GOR). Since an upper limit of produced GOR has been considered for each well in the simulation model, the well stops producing oil if its GOR becomes greater than the pre-defined limit in the model. The well, however, can continue to produce when the simulator makes sure its GOR will not exceed the limit. Therefore, some wells may experience a sequence of opening and shutting periods that has an adverse effect on cumulative oil production. For the injection rates less than 500 MMSCFD, the cumulative oil production takes advantage of higher reservoir pressure if the injection rate is increased. However, the speed of GOC coming down is not so great to have a severe effect on the cumulative oil production. In summary, the gravity drainage is very slow process and its effects are felt in the long term. A sensitivity analysis on the injection rate helps to find an optimal one which can postpone the problem of additional gas production. The gas injection rate of 500 MMSCFD was selected for further analysis in this work. 

simulation results and actual data after history matching process; a the reservoir cumulative gas production, $\mathbf{b}$ static gas pressure in the well\#1, $\mathbf{c}$ flowing oil pressure in the well\#3
Fig. 8 Comparison between
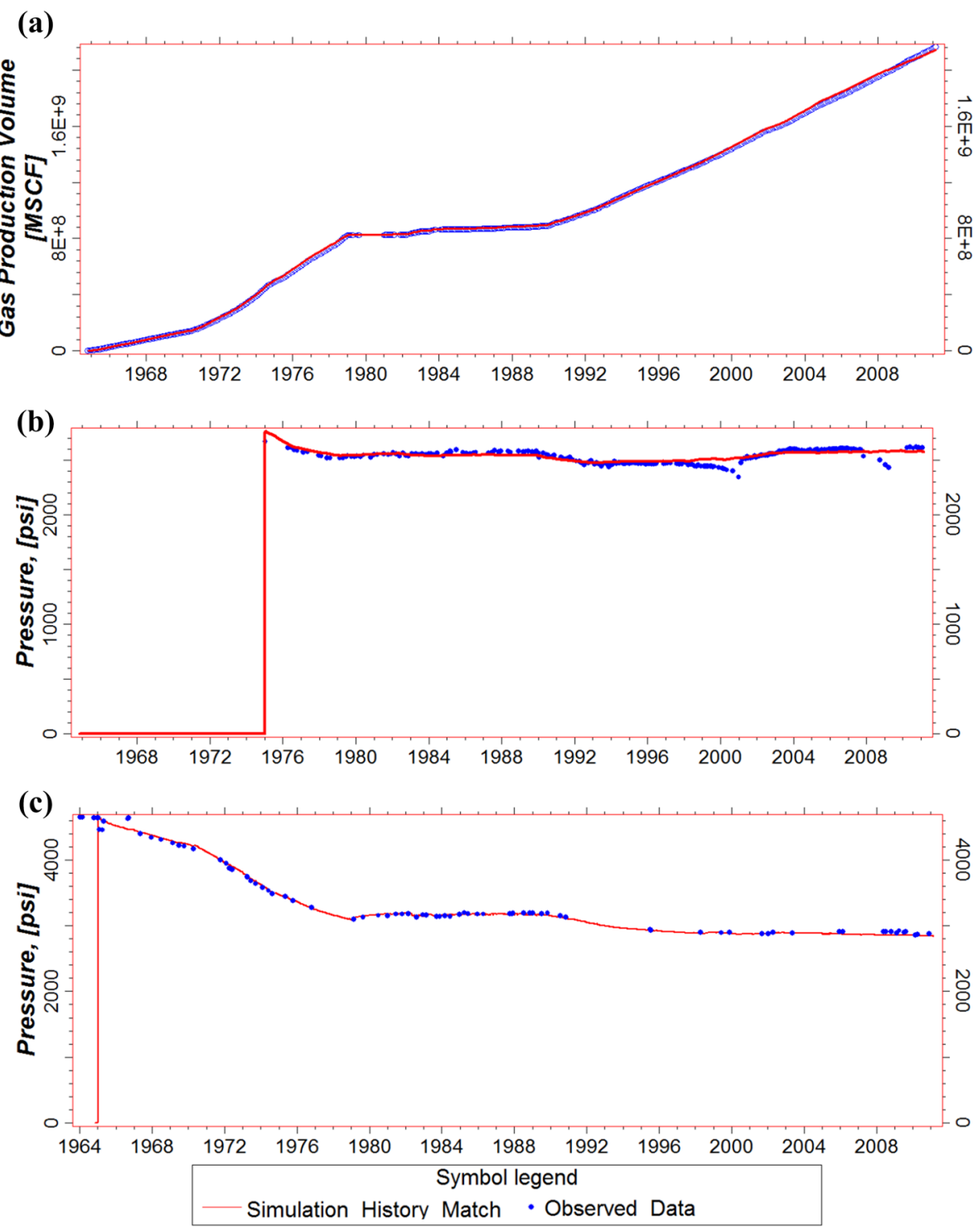

Fig. 9 The reservoir pressure in different rates

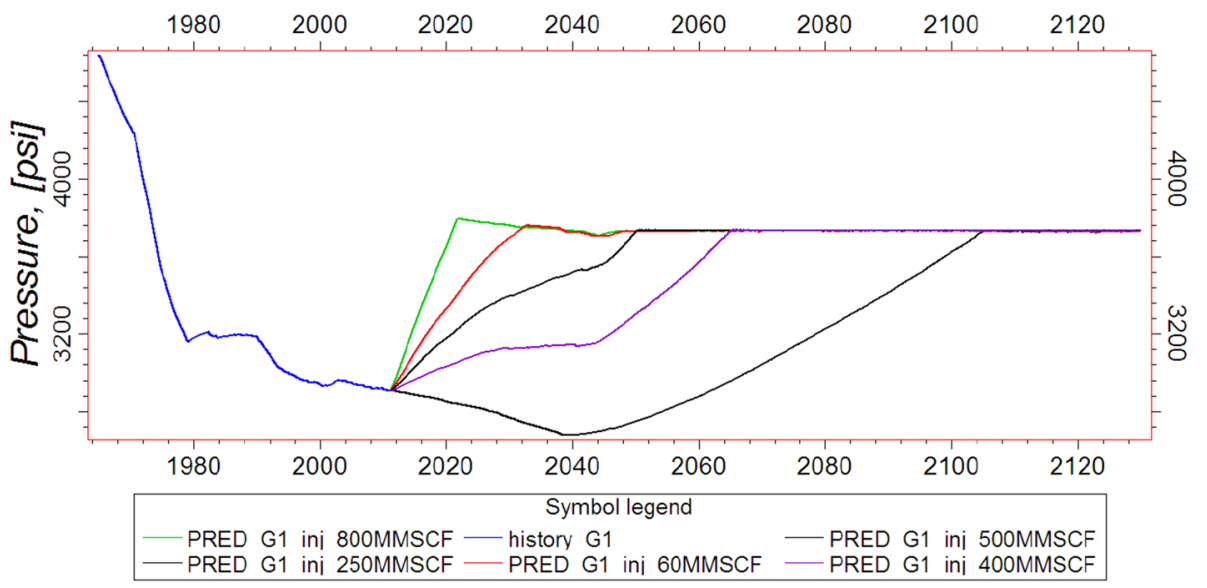


Fig. 10 Cumulative oil production for different gas injection rates

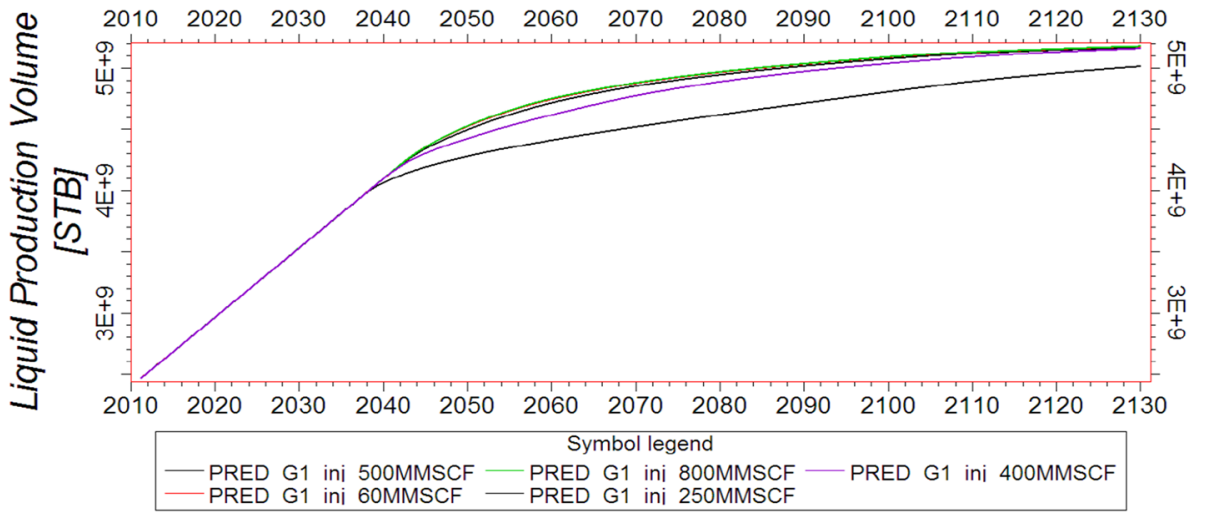

\section{Results and discussion}

The simulator used (i.e., ECLIPSE) provides the user with some keywords to easily estimate the contribution of mechanisms such as fluid expansion or water drive to the oil production. The simulator also has been well equipped to include/exclude the process of gravity drainage in/from the simulation of a fractured reservoir. However, it has no specific keyword to find the volume of oil produced by the gravity drainage itself. The approach of this work to resolve the issue involves comparing the results of 2 different simulation cases; a case with activated gravity drainage and the other with inactivated gravity drainage. In other words, the amount of oil produced in a scenario with active gravity drainage is compared with the amount of oil produced in the same scenarios in which gravity drainage is inactive. It is considered that the difference in oil production in these two cases is due to gravity drainage mechanism. Since different mechanisms participate in the oil production from a reservoir according to their effectiveness, eliminating or weakening of each of them clearly leads to an increase in the share of others.

Two different methods may be used to calculate the share of oil recovery due to gravity drainage. In the first method, the contribution of the gas-influx mechanism to oil production is compared between the two cases in which the gravity drainage is active or inactive. In the second method, the change in the average gas saturation is determined for the matrix blocks located in the gas-invaded zone. The latter method is based on the fact that in the gas oil system the oil is the wetting phase and tends to remain in the matrix. It means a matrix block is expected to hardly produce oil unless the gravity drainage is activated.

The contribution of gravity drainage to oil recovery is determined in 2 different scenarios; a natural depletion scenario, and a gas injection scenario with the rate of 500 MMSCFD. The comparison of their results helps not only to investigate the effect of gravity drainage on oil recovery factor but also it can convey an image of gravity drainage improvement by gas injection.

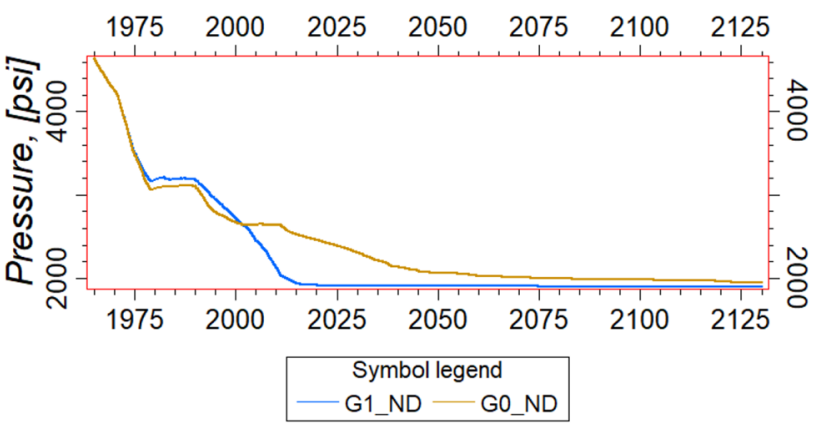

Fig. 11 Oil pressure in natural depletion scenarios with active/inactive gravity drainage

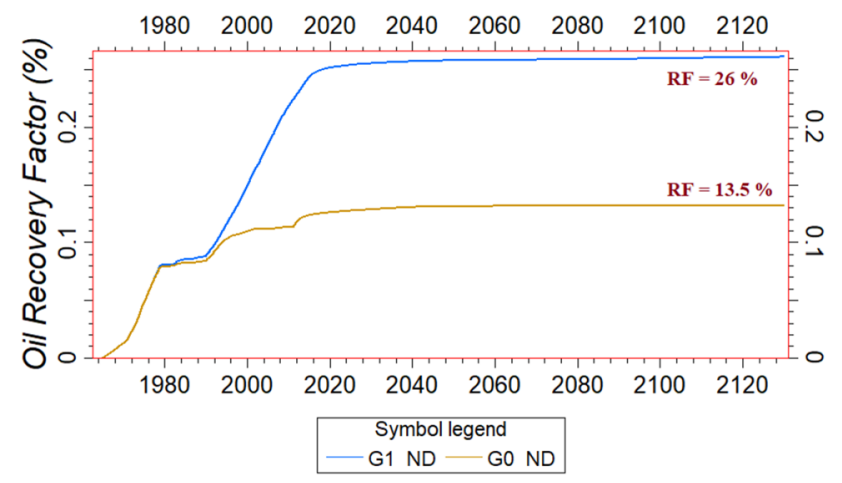

Fig. 12 Oil recovery factor for natural depletion scenarios with active/inactive gravity drainage

\section{Natural depletion scenario}

Gas injection during its history was removed from the model to simulate the natural depletion scenario. Figures 11 and 12 show the pressure and recovery factor of the reservoir in the simulation models with active/inactive gravity drainage, respectively. Figure 12 demonstrates that the oil recovery factor increases from 13.5 to $26 \%$ by the activation of GRAVDR keyword in the used simulator. 
Moreover, the amount of oil produced by each of the existing mechanisms in both active/inactive states of gravity drainage is given in Table 3.

Table 3 shows the cumulative oil production due to gas influx increases from 0.42 to 1.85 MMMSTB if the gravity drainage is activated. It implies that the mechanism of gravity drainage has a profound impact on oil production from a fractured reservoir. In other words, 1.43 billion barrels of excess oil are produced by activating gravity drainage in the reservoir. This production comprises about $50 \%$ of the field recovery factor relative to the cumulative production of 2.87 billion barrels of oil.
In terms of the mechanism participation in total production, the share of gas influx rises from $29 \%$ in the case with inactive gravity drainage to $64 \%$ in the one with active the mechanism. As the share of this mechanism in oil production increases, the share of water influx, oil expansion and rock compaction mechanisms decrease by about half.

\section{Gas injection with optimal flow}

In this scenario, gas is injected with the rate of 500 MMSCFD at the end of production history. After the gas pressure reaches the initial pressure in the crest of the
Table 3 Comparison of oil produced by different mechanisms in active/inactive gravity drainage

\begin{tabular}{lllllc}
\hline Mechanisms & \multicolumn{2}{l}{ ND_G1 (active gravity drainage) } & & \multicolumn{2}{l}{ ND_G0 (inactive gravity drainage) } \\
\cline { 2 - 2 } $\begin{array}{lllll}\text { Cumulative oil produc- } \\
\text { tion MMMSTB }\end{array}$ & Percent (\%) & & $\begin{array}{l}\text { Cumulative oil produc- } \\
\text { tion MMMSTB }\end{array}$ & Percent (\%) \\
\hline Gas influx & 1.85 & 64.4 & & 0.42 & 28.66 \\
Water influx & 0.73 & 25.5 & & 0.74 & 50.78 \\
Oil expansion & 0.28 & 9.73 & & 0.29 & 19.71 \\
Rock compaction & 0.01 & 0.43 & & 0.01 & 0.86 \\
TOTAL & 2.87 & 100 & 1.45 & 100 \\
\hline
\end{tabular}

Fig. 13 Oil pressure in gas injection scenarios with active/ inactive gravity drainage
Fig. 14 Oil recovery factor in gas injection scenarios with active/inactive gravity drainage
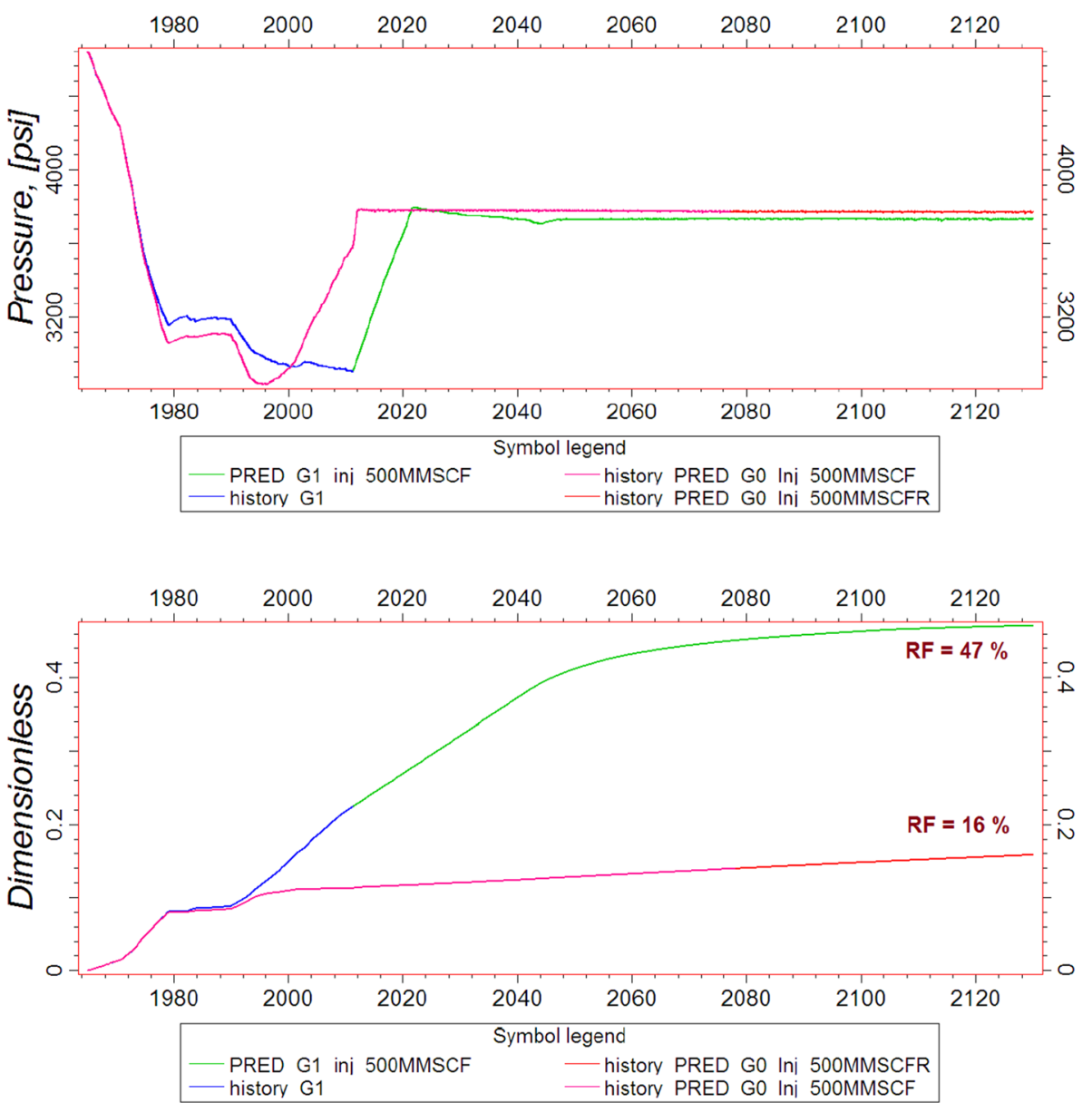
Table 4 Comparison of oil produced by different mechanisms

\begin{tabular}{|c|c|c|c|c|}
\hline \multirow[t]{2}{*}{ Mechanisms } & \multicolumn{2}{|c|}{$\begin{array}{l}\text { G1_Inj_500MMSCF (active gravity drain- } \\
\text { age) }\end{array}$} & \multicolumn{2}{|c|}{$\begin{array}{l}\text { G0_Inj_500MMSCF (inactive gravity } \\
\text { drainage) }\end{array}$} \\
\hline & $\begin{array}{l}\text { Cumulative oil produc- } \\
\text { tion MMMSTB }\end{array}$ & Percent $(\%)$ & $\begin{array}{l}\text { Cumulative oil produc- } \\
\text { tion MMMSTB }\end{array}$ & Percent (\%) \\
\hline Gas influx & 4.672 & 90.2 & 0.979 & 56.3 \\
\hline Water influx & 0.269 & 5.2 & 0.272 & 15.6 \\
\hline Oil expansion & 0.232 & 4.5 & 0.485 & 27.9 \\
\hline Rock compaction & 0.005 & 0.1 & 0.005 & 0.26 \\
\hline TOTAL & 5.178 & 100 & 1.741 & 100 \\
\hline
\end{tabular}

Table 5 Changes in the matrix average saturations in the gas-invaded area

\begin{tabular}{lllllc}
\hline Fluid type & $\begin{array}{l}\text { G1_Inj_500MMSCF } \\
\text { (active gravity drainage) }\end{array}$ & & $\begin{array}{l}\text { G0_Inj_500MMSCF } \\
\text { (inactive gravity drain- } \\
\text { age) }\end{array}$ \\
\cline { 2 - 3 } \cline { 5 - 6 } & $\begin{array}{l}\text { Initial ave. } \\
\text { saturation }\end{array}$ & $\begin{array}{l}\text { Final ave. } \\
\text { saturation }\end{array}$ & & $\begin{array}{l}\text { Initial ave. } \\
\text { saturation }\end{array}$ & $\begin{array}{l}\text { Final ave. } \\
\text { saturation }\end{array}$ \\
\hline Gas & 0 & 27.9 & & 1.9 \\
Water & 35.5 & 35.7 & & 35.5 & 35.7 \\
Oil & 64.5 & 36.4 & 64.5 & 62.4 \\
Difference & 28.1 & & 2.1 & \\
\hline
\end{tabular}

reservoir, the gas injection flow is reduced to stabilize the pressure.

Figures 13 and 14 show the reservoir pressure and recovery factor in the scenario with 500 MMSCFD gas injections under active/inactive gravity drainage, respectively.

The oil recovery factor increases from 16 to $47 \%$ by activating the GRAVDR keyword in the used simulator. The amounts of oil produced by each mechanism in both active/ inactive states are given in Table 4.

The increase in oil produced by gas influx from 0.98 to 4.67 MMMSTB is due to the activation of gravity drainage. The total production of the reservoir is 5.18 MMMSTB of which 3.67 MMMSTB are produced by gravity drainage. This volume is equal to $71 \%$ of the ultimate reserve of the reservoir. By the activation of gravity drainage, the participation of the gas influx mechanism in oil production has almost doubled and the share of other mechanisms, especially water influx, has been drastically reduced.

The activation of gravity drainage enables the gas phase to enter the matrix block which results in oil displacement. Consequently, the distribution of fluid saturations in the matrix block will change. Table 5 reports the initial and final saturations averaged over all the matrix blocks corresponding to the gas-invaded zone.

Since the initial reservoir pressure is greater than the bubble point pressure, no gas cap is present in the reservoir and hence the initial gas saturation is zero. While producing

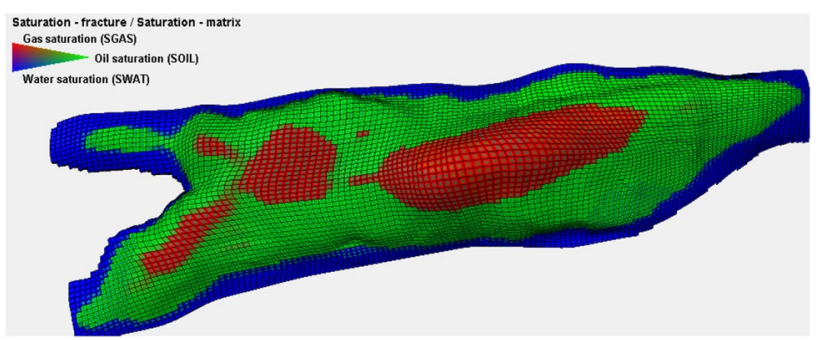

Fig. 15 Fluids saturation of the matrices/fractures before start of gas injection with active gravity drainage

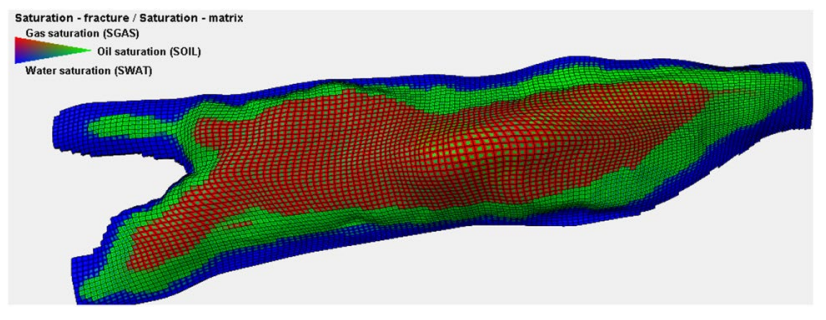

Fig. 16 Fluids saturation of the matrices/fractures before start of gas injection with inactive gravity drainage

oil from the reservoir, the reservoir pressure declines and a gas cap forms a few years after the start of production. The matrix blocks at lower depth are influenced more greatly and will encounter more gas volume. Although gas injection at the rate of 500 MMSCFD can re-pressurize some parts of the reservoir to values higher than the bubble point pressure, the gas phase may not disappear entirely due to the option of restricted gas dissolving in the liquid phase. In other parts, the pressure may not even reach the bubble point pressure. That is why a small average of gas saturation $(1.9 \%)$ can be found in the matrix blocks of gas-invaded zone in the longterm for the case in which the gas is not permitted to enter the matrix (i.e. inactive gravity drainage).

The average of matrix gas saturation in the gas-invaded zone changes from zero to 27.9 when gravity is active. The change determines the amount of gas that enters the matrix in this scenario. 
Figures 15 and 16 show the fluid saturation of the matrices and fractures in the reservoir, before the start of gas injection in the active and inactive states of gravity drainage, respectively. By comparing these figures, it is observable that by activating the GRAVDR keyword, the released gas enters the matrix and the volume of the gas-invaded fractures decreases, but in the case of removing the keyword, due to the gas resistance to entering the matrix, the released gas remains in the fractures and occupies a very large volume of them.

According to the information in the previous table, $40 \%$ of the matrix oil is produced in the gas-invaded area due to gravity drainage. The volume of the gas-invaded area to the whole reservoir is $77 \%$. Therefore, the oil produced from the matrix constitutes $60 \%$ of the total of recovery factor.

\section{Effect of capillary pressure curves of gas/oil system on gravity drainage mechanism}

Capillary pressure is inversely related to the reservoir pressure; it means the capillary pressure increases as the reservoir pressure decreases. These changes occur due to changes in interfacial tension between fluids with the pressure as shown in Fig. 2. It is emphasized that the gas/oil capillary pressure curves of Fig. 5 are presented at the reference pressure of 2600 psi. According to Fig. 2, the interfacial tension at the reference pressure is about $4.5 \mathrm{dyne} / \mathrm{cm}$ but it is around $2.2 \mathrm{dyne} / \mathrm{cm}$ at the post-injection stabilized pressure of 3775 psi. Figure 17 shows the capillary pressure curves of all rock types after correcting the pressure effect. In these curves, the maximum capillary pressure is $4 \mathrm{psi}$.

Considering the block height of $20 \mathrm{ft}$ for all matrices, oil and gas pressure gradients of 0.284 and $0.09 \mathrm{psi} / \mathrm{ft}$, respectively, the maximum pressure difference at the bottom face of the matrix due to the oil and gas columns is calculated about 3.9 psi if an oil-saturated matrix is surrounded by neighboring fractures completely filled with gas. Certainly, with the entry of gas into the matrix, the oil begins to drain

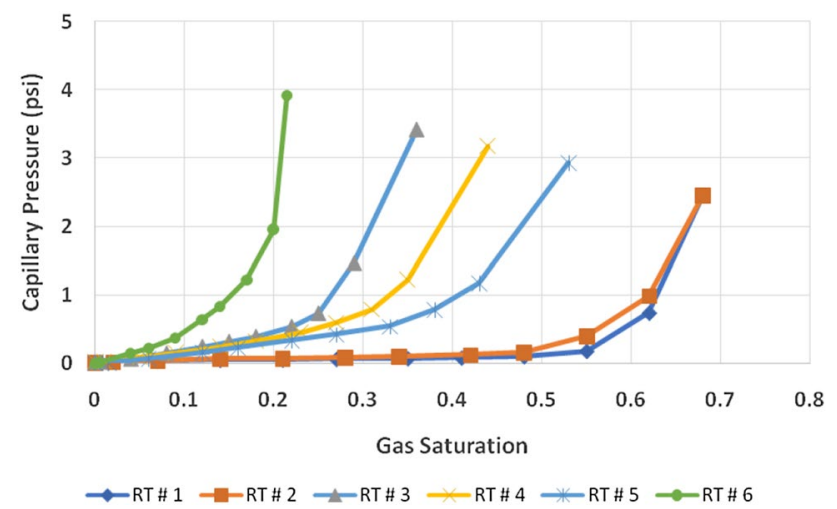

Fig. 17 Pressure-corrected capillary pressure curves of all rock types into the fractures; this process will continue until the capillary and gravity forces reach equilibrium. In order to calculate the amount of oil drained from each rock type, the following assumptions have been considered.

1. The whole of each matrix block consists of only one rock type;

2. The capillary continuity between neighboring matrix blocks is not allowed;

3. A linear relationship exists between the average gas saturation and the oil column in the matrix.

The first assumption is implicitly considered in flow simulation because one particular rock type is assigned to each simulation grid and therefore to all matrix blocks contained in the gird. Different simulation grids, however, may have dissimilar rock types. The second assumption ensures that the effective block height used for the calculation of gravity force is equal to the assigned one ( $20 \mathrm{ft}$ in this study). For the third assumption, one may visualize the gas penetrating into the top of the matrix forms a front that moves downward. By the movement, not only the volume of gas-invaded zone grows steadily, but also the gas saturation behind the front increases due to oil drainage. The average gas saturation along the total height of the matrix can be deemed to be linearly related to the length of the gas column. The last assumption describes the idea in oil column rather than the gas one as the sum of two columns is constant and equal to the matrix block height.

The gas saturation is directly proportional to the capillary pressure; the height of oil column measured from the bottom face of the matrix is related to the gravity force. The gravity force is usually represented by the pressure difference between the oil and gas columns $\left(\Delta \rho_{\mathrm{go}} \times g \times h\right)$. Consequently, as the gas front moves downward, the gas saturation and the capillary pressure increases, whereas the oil column and the gravity force reduces. Figures 18 and 19 show curves

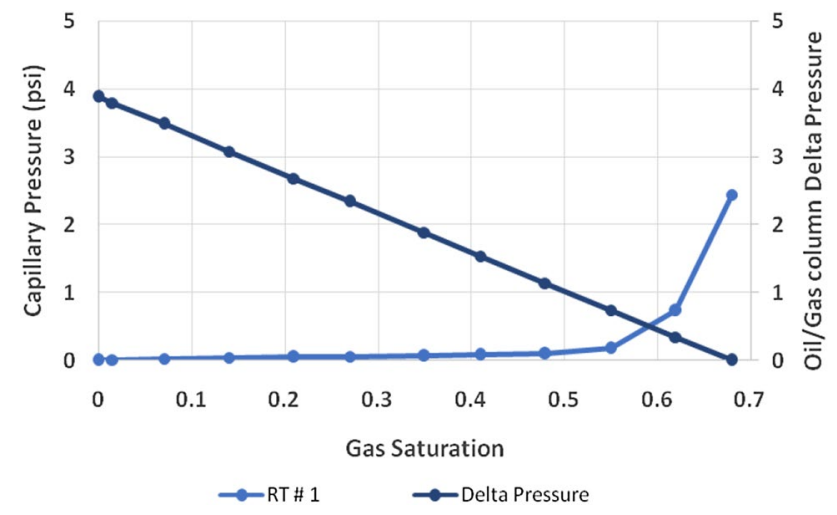

Fig. 18 Curves of the pressure difference and capillary pressures for RT\#1

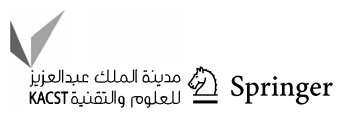




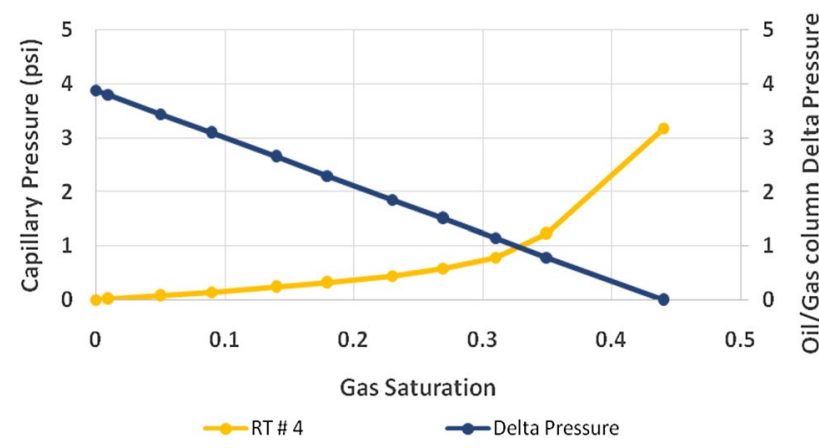

Fig. 19 Curves of the pressure difference and capillary pressures for RT\#4

Table 6 The fluid saturations at gravity-capillary condition for each rock type of the pressure difference due to the fluids column along with the capillary pressures for the two rock types.

The intersection of these two lines actually indicates the gas saturation in the matrix when the balance between the two forces is achieved. In other words, the displacement of the matrix oil by the gas will continue only until it reaches the calculated saturation. This saturation can be used to estimate the oil recovery factor for each rock type. A summary of the results for all types of rocks is given in Table 6. The table shows gravity drainage leads to a smaller recovery factor in the rock types with higher capillary pressure. These rock types are expected to have smaller pore throat which the non-wetting gas phase may hardly enter. In this reservoir, the rock type \#6 is usually found at the base of the reservoir near

\begin{tabular}{lrlllll}
\hline Rock type & Freq & Swc & Soi & $\Delta$ Sg & So (final) & $\begin{array}{l}\text { Est. recov- } \\
\text { ery factor } \%\end{array}$ \\
\hline 1 & 11.26 & 0.1 & 0.9 & 0.58 & 0.32 & 64.44 \\
2 & 0.86 & 0.15 & 0.85 & 0.57 & 0.28 & 67.06 \\
3 & 13.75 & 0.31 & 0.69 & 0.27 & 0.42 & 39.13 \\
4 & 19.78 & 0.3 & 0.7 & 0.33 & 0.37 & 47.14 \\
5 & 8.59 & 0.27 & 0.73 & 0.4 & 0.33 & 54.79 \\
6 & 45.76 & 0.48 & 0.52 & 0.16 & 0.36 & 30.77 \\
\hline
\end{tabular}

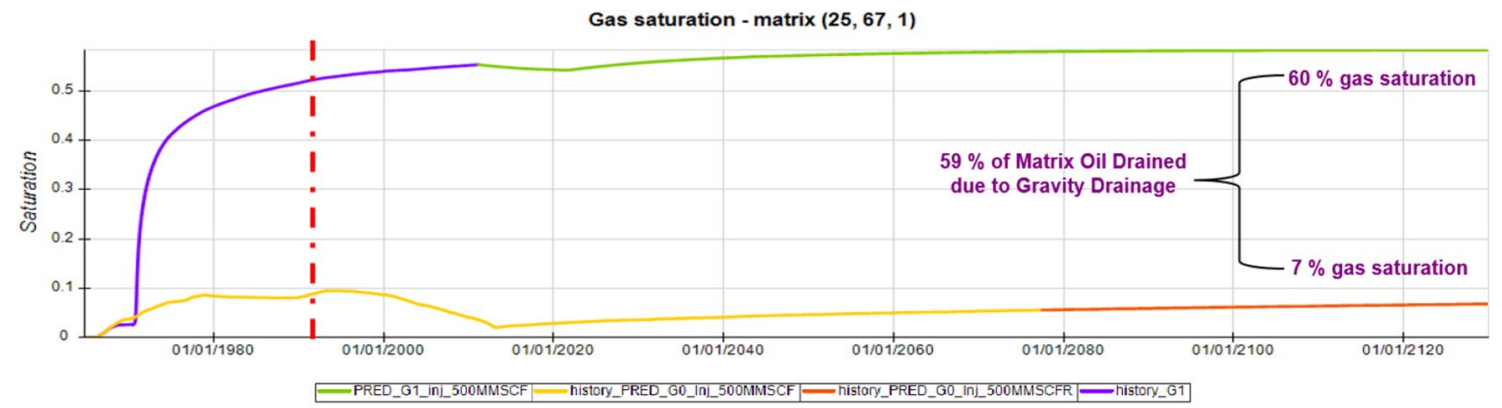

Fig. 20 Gas saturation changes of RT\#1 in the crestal area in active/inactive gravity drainage

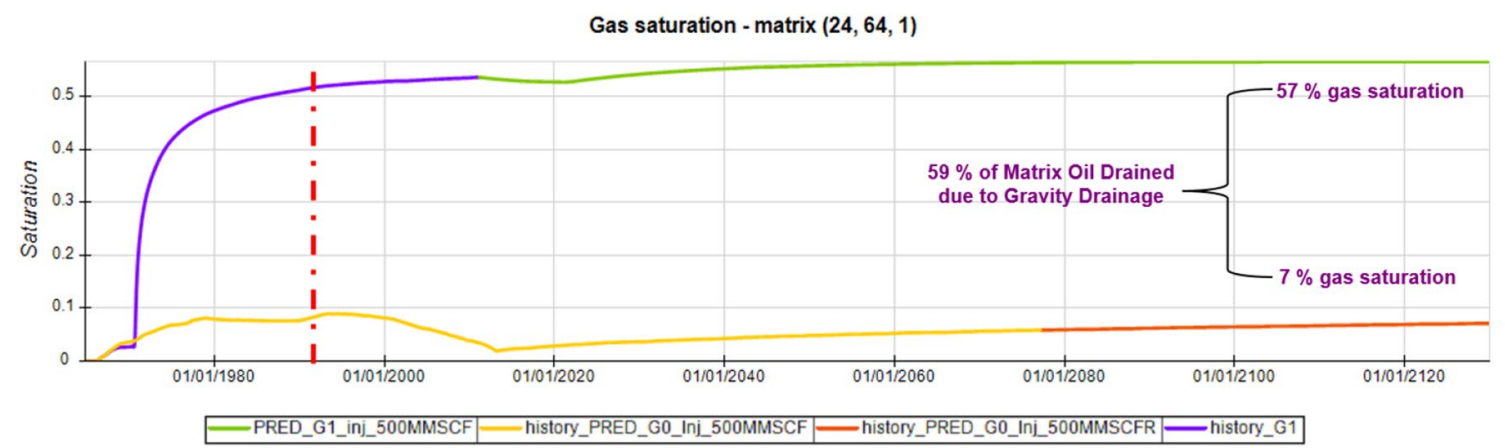

Fig. 21 Gas saturation changes of RT\#2 in the crestal area in active/inactive gravity drainage 


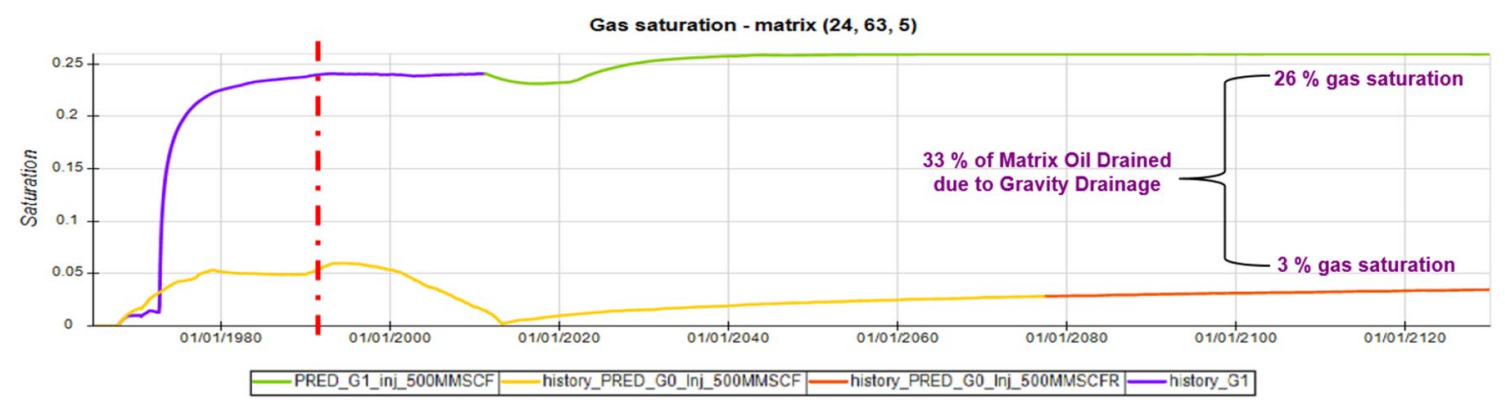

Fig. 22 Gas saturation changes of RT\#3 in the crestal area in active/inactive gravity drainage

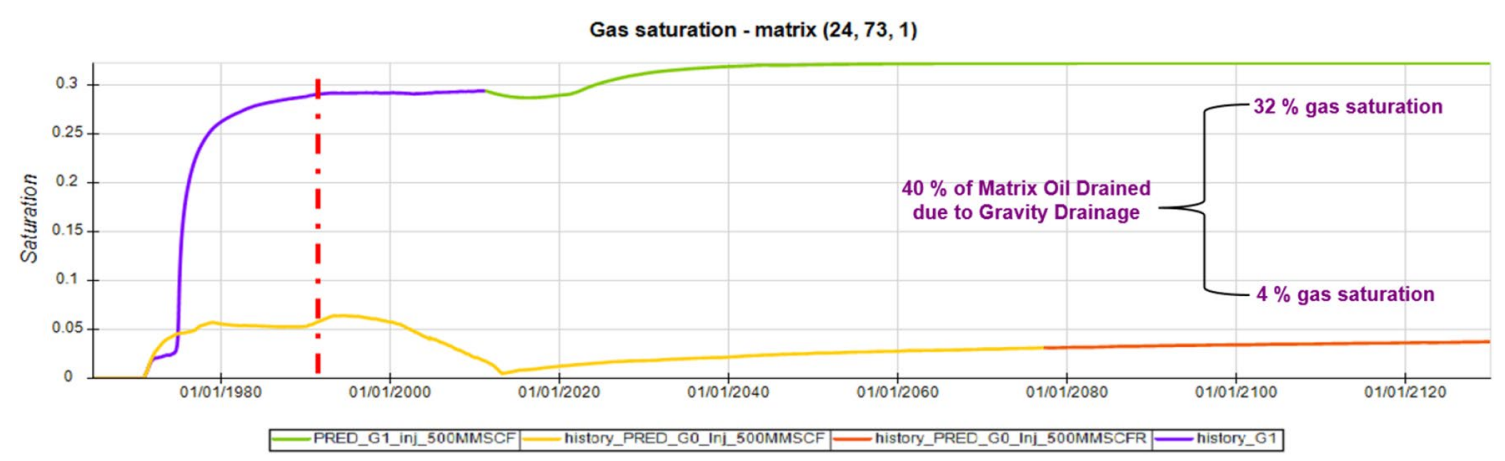

Fig. 23 Gas saturation changes of RT\#4 in the crestal area in active/inactive gravity drainage

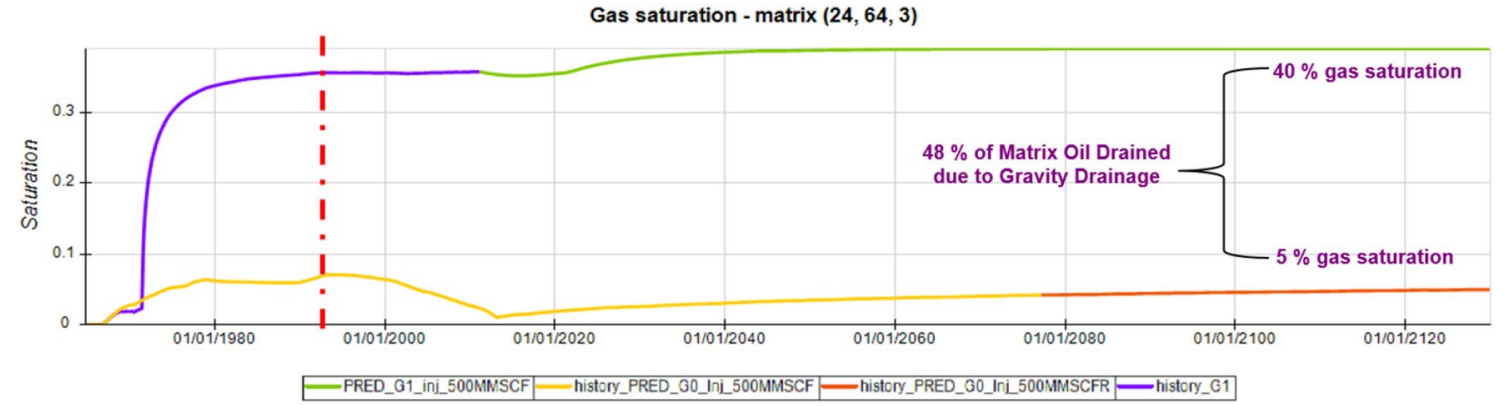

Fig. 24 Gas saturation changes of RT\#5 in the crestal area in active/inactive gravity drainage

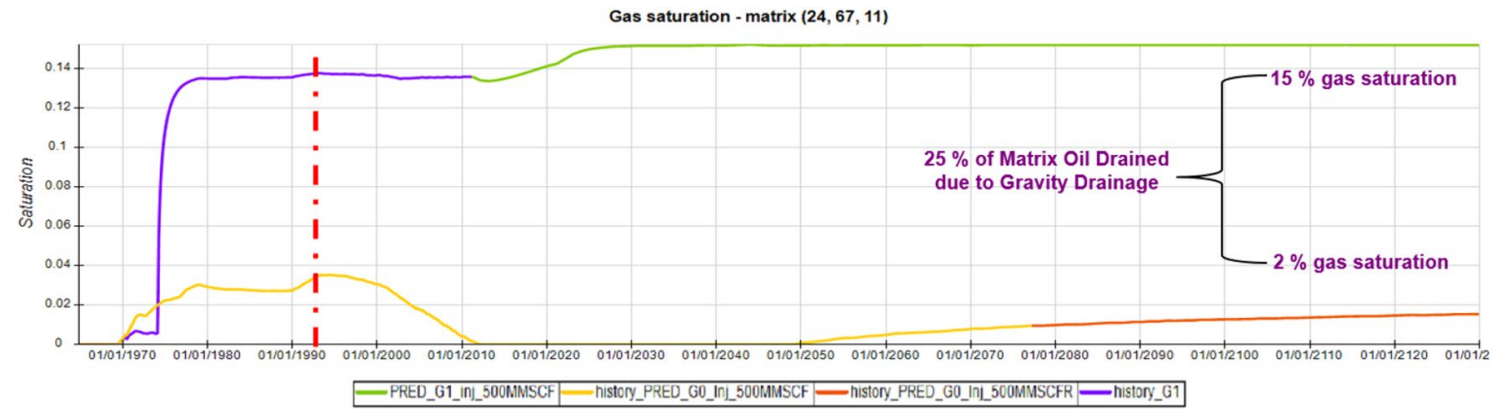

Fig. 25 Gas saturation changes of RT\#6 in the crestal area in active/inactive gravity drainage 
the water/oil contact, whereas other types are distributed throughout the oil column or gas-invaded zone.

Figures 20, 21, 22, 23, 24 and 25 show the gas saturation changes of different rock types in the crest of the reservoir for both cases of active/inactive gravity drainage.

According to these figures, it is clear that in the crestal area, immediately after the fractures are occupied by gas, gravity drainage becomes activated and up to $60 \%$ of the oil is drained from matrices. This is due to the special shape of the Pc diagrams, which has led to a very large impact on gravity drainage of the production of this reservoir. Moreover, comparison of the final gas saturations obtained from the simulator (Figs. 20, 21, 22, 23, 24 and 25) with the corresponding values reported in Table 6 shows a satisfactory agreement. This indicates that capillary curves can be used to estimate the recovery factor of gravity drainage.

\section{Effect of block height on gravity drainage mechanism}

The gravity, as the driving force, depends on two factors; the density difference between phases (usually oil and gas) and the effective matrix block height. This section evaluates the effect of matrix block height on the reservoir performance.

It is well known that the height of a matrix block must be greater than the capillary threshold height, otherwise no oil can drain from the matrix. At any height along the matrix block, the wetting phase (oil) saturation gradually decreases until the resistant capillary force becomes strong enough to stop oil flowing. That is why the gravity drainage is more efficient for matrix blocks with greater height.

Figure 26 shows the sensitivity analysis for comparing the recovery factor in the case of optimal gas injection rate at 3 different matrix block heights. The figure shows that an increase in the block height from 10 to $20 \mathrm{ft}$ improves the recovery factor by about $4 \%$. However, if the block height changes from 20 to $30 \mathrm{ft}$, the recovery factor increases by less than $2 \%$.

Figure 27 compares the behavior of reservoir pressure at 3 cases with different matrix block heights. It shows the case in which the matrix block height is considered $10 \mathrm{ft}$ has a larger pressure drop than other cases even though gas is being injected into the reservoir. In this case, oil production under weaker gravity drainage mechanism reduces the oil
Fig. 26 Effect of matrix block height on the recovery factor
Fig. 27 Effect of matrix block height on the reservoir pressure
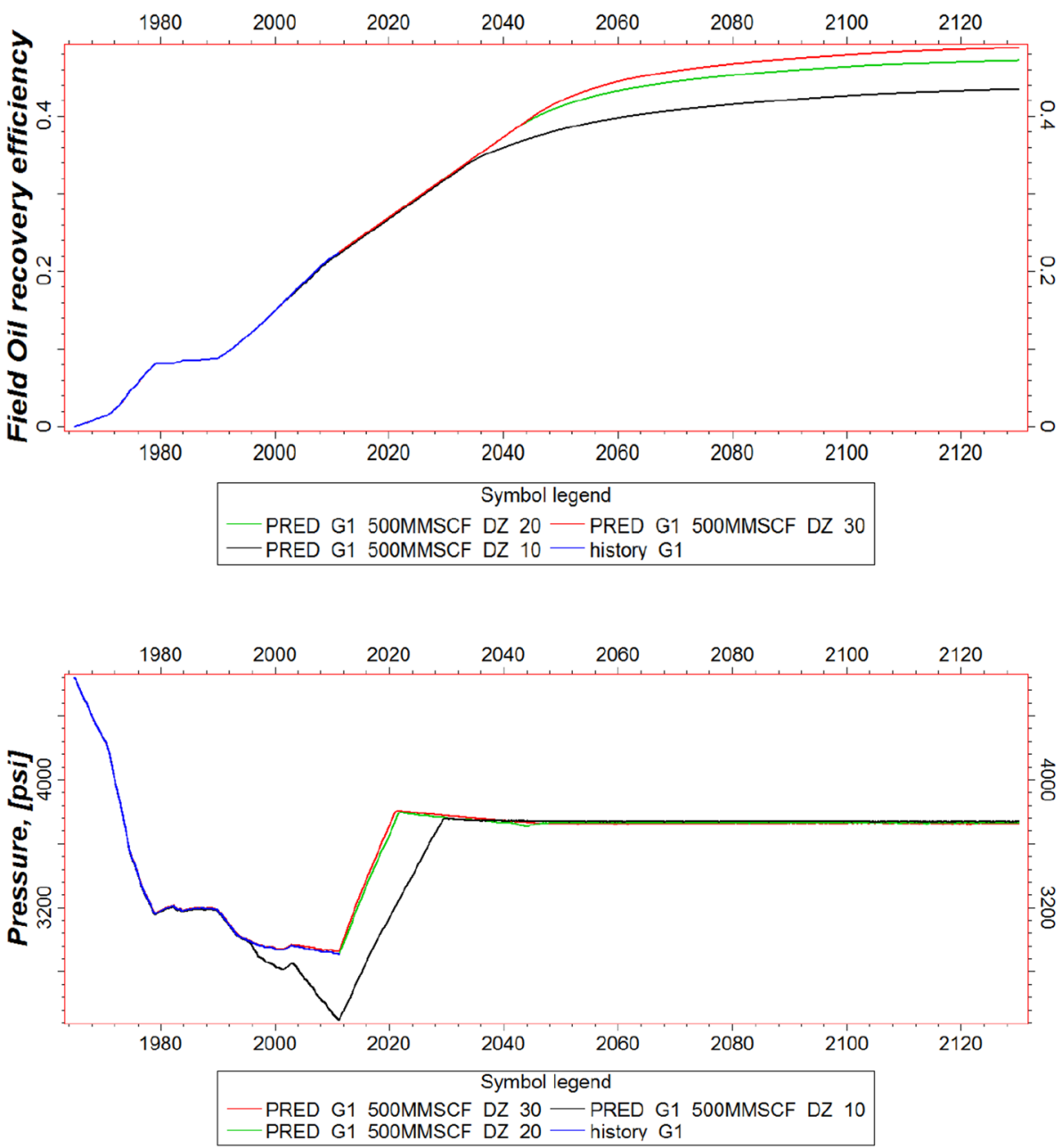
column remarkably. When the gas/oil contact falls below the completion depth of some production wells, a great volume of gas produced from the gas cap results in significant pressure drop. For the cases with block height of 20 or $30 \mathrm{ft}$, the gravity drainage is effective enough to reasonably maintain the pressure when the reservoir is under production.

\section{Conclusion}

The paper discussed how the simulation results could be analyzed to extract the contribution of gravity drainage from that of gas influx. The substantial effect of this mechanism on recovery factor was also highlighted. The results showed that the recovery factor of gravity drainage might reach as high as $40 \%$ in the gas-invaded zone of a real fractured reservoir under gas injection. This volume of oil made up more than $60 \%$ of the oil produced from the reservoir; the contribution that was solely greater than the sum of other mechanisms' contributions.

A simple graphical method was developed to estimate the ultimate recovery factor of gravity drainage. The results were proved to be in a good agreement with the ones obtained from the simulation model. Moreover, they illustrated that the capillary pressure curve could significantly influence the efficiency of gravity drainage as the mechanism produced $25-59 \%$ of the oil in the matrix depending on the rock type. Gas injection was applied to the fractured reservoir to improve the performance of gravity drainage. It increased the reservoir pressure that led to the lower IFT and hence capillary pressure. As a result, greater recovery factor was found in gas injection scenario than in natural depletion one. Finally, the sensitivity analysis to the block height showed that it would have a positive effect on oil recovery.

It is emphasized that the results of this study are based on the analysis of actual behavior for one particular fractured reservoir. However, one may be faced with some cases whose behaviors are quite different from the presented performance due to prevailing other phenomena. Diffusion especially in tight reservoirs and capillary continuity are among those factors that may have an impact on gravity drainage. These issues are out of the scope of the present work and they will be discussed in future studies.

Funding This research received no specific funding.

Open Access This article is licensed under a Creative Commons Attribution 4.0 International License, which permits use, sharing, adaptation, distribution and reproduction in any medium or format, as long as you give appropriate credit to the original author(s) and the source, provide a link to the Creative Commons licence, and indicate if changes were made. The images or other third party material in this article are included in the article's Creative Commons licence, unless indicated otherwise in a credit line to the material. If material is not included in the article's Creative Commons licence and your intended use is not permitted by statutory regulation or exceeds the permitted use, you will need to obtain permission directly from the copyright holder. To view a copy of this licence, visit http://creativecommons.org/licenses/by/4.0/.

\section{References}

Abbasi M, Rostami P, Moraveji MK, Sharifi M (2018) Generalized analytical solution for gravity drainage phenomena in finite matrix block with arbitrary time dependent inlet boundary condition and variable matrix block size. J Petrol Sci Eng 167:227-240. ISSN 0920-4105

Ahmed T (2018) Reservoir engineering handbook, 2nd edn. Gulf Professional Publishing, Houston

Bahari Moghaddam M, Rasaei MR (2015) Experimental study of the fracture and matrix effects on free-fall gravity drainage with micromodels. SPE J 20(02):324-336

Boerrigter PM, Verlaan ML, Yang D (2007) EOR methods to enhance gas oil gravity. In: SPE/EAGE reservoir characterization and simulation conference, Abu Dhabi, UAE

Clemens T, Wit K (2001) The effect of fracture spacing on gas/oil gravity drainage in naturally fractured reservoirs. In: SPE 71507 presented at the $2001 \mathrm{SPE}$ annual technical conference and exhibition, New Orleans, LO. https://doi.org/10.2118/71507-MS

Dumore JM, Schols RS (1974) Drainage capillary pressure function and influence of connate water. Soc Pet Eng J 14:437-444

Hagoort J (1980) Oil recovery by gravity drainage. Soc Petrol Eng J 20(03):139-150

Pirson SJ (1958) Elements of oil reservoir engineering, 2nd edn. McGraw-Hill, New York, pp 635-693

Rahmati N, Rasaei M (2019) Quantifying the reimbibition effect on the performance of gas-oil gravity drainage in fractured reservoirs: mathematical modelling. Can J Chem Eng 97:1718-1728. ISSN 0008-4034

Sajjadian VA, Danesh A, Tehrani DH (1999) Laboratory studies of gravity drainage mechanisms in fractured carbonate reservoir reinfiltration. SPE 54003

Tan CT, Firoozabadi A (1995) Theoretical analysis of miscible displacement in fractured porous media by a one-dimensional model, Part one and two. JCPT. https://doi.org/10.2118/ 95-02-02

Verlaan M, Boerrigter P (2006) Miscible gas/oil gravity drainage. In: SPE 103990, first international oil conference and exhibition in Mexico, 31 August-2 September, Cancun, Mexico

Zendehboudi S, Chatzis I, Shafiei A, Dusseault MB (2011) Empirical modeling of gravity drainage in fractured porous media. Energy Fuels 25(3):1229-1241. ISSN 0887-0624

Zobeidi K, Fassihi M (2018) Block to block interactions and their effects on miscibility gravity drainage in fractured carbonate reservoirs, experimental and analytical results. J Petrol Sci Eng 164:696-708. ISSN 0920-4105

Zobeidi K, Fassihi MR, Rasaei MR (2015a) Description of the results of experiments on developed miscibility with nonequilibrium gas/ oil gravity drainage. SPE J 21:0827-0838

Zobeidi K, Rasaei MR, Fassihi MR (2015b) Simulation of one-phase miscible gravity drainage performance of a stack of matrix blocks. JPM 18(11):1107-1118

Publisher's Note Springer Nature remains neutral with regard to jurisdictional claims in published maps and institutional affiliations. 